Nicotine \& Tobacco Research Advance Access published June 5, 2015

Nicotine \& Tobacco Research, 2015, 1-7

doi:10.1093/ntr/ntv111

Original investigation

\title{
The Social Patterning of Tobacco Use Among Women in Jordan: The Protective Effect of Education On Cigarette Smoking and the Deleterious Effect of Wealth on Cigarette and Waterpipe Smoking
}

\author{
Mohammed Jawad MBBS ${ }^{1,2}$, Sawsan Abdulrahim PhD³, Aref Daouk MD4 \\ 'Department of Primary Care and Public Health, Imperial College London, Hammersmith, United Kingdom; ${ }^{2}$ Academic \\ Unit of Primary Care and Population Sciences, University of Southampton, Southampton, United Kingdom; ${ }^{3}$ Department \\ of Health Promotion and Community Health, Faculty of Health Sciences, American University of Beirut, Beirut, Lebanon; \\ ${ }^{4}$ Department of Health Management and Policy, Faculty of Health Sciences, American University of Beirut, Beirut, Lebanon \\ Corresponding Author: Sawsan Abdulrahim, PhD, Department of Health Promotion and Community Health, Faculty of \\ Health Sciences, American University of Beirut, PO Box 11-2036, Riad El Solh, Beirut 1107 2020, Lebanon. Telephone: 961- \\ 1-350-000 Ext: 4656; Fax: 961-1-744-470; E-mail: sawsana@aub.edu.lb
}

\begin{abstract}
Introduction:The presence of social inequalities in tobacco-use has been fully recognized in the international literature. Even though cigarette and waterpipe tobacco smoking (WTS) are prevalent in the Arab region, the literature has not addressed the social determinants of the impending tobacco epidemic. This study examined the socioeconomic patterning of cigarette and WTS among Jordanian women. Methods: We analyzed pooled data from four waves of the Jordan Demographic and Health Surveys: 2002 ( $N=5851) ; 2007$ ( $N=10$ 654); 2009 ( $N=9879)$, and $2012(N=11$ 113). We specified logistic regression models to test the association between education and household wealth and the two outcome measures, cigarette and WTS, adjusting for other covariates. For each outcome, we ran time-unadjusted and time-adjusted logistic models.

Results: Cigarette smoking prevalence among Jordanian women remained almost constant (around 10\%) between 2002 and 2012. WTS prevalence steadily increased from 4.1\% in 2002 to $10.2 \%$ in 2012. Increasing education predicted lower odds of cigarette smoking, whereas increasing household wealth weakly predicted higher odds. As to WTS, increasing household wealth strongly predicted higher odds of use.

Conclusions: Among Jordanian women, increasing education is protective against cigarette smoking. Household wealth, on the other hand, exerts a deleterious effect on both forms of tobacco consumption, particularly WTS. This pattern shows that Jordan has not fully undergone the socioeconomic crossover in tobacco prevalence which characterizes high-income countries. Future control policies should aim to decrease prevalence but also preempt increasing social inequalities in tobacco use.
\end{abstract}

\section{Introduction}

Tobacco use is a major public health problem worldwide, particularly in Arab countries where it contributes to a large proportion of the noncommunicable disease burden. ${ }^{1,2}$ The Arab region is also experiencing an epidemic of waterpipe tobacco smoking (WTS) particularly among youth. ${ }^{3,4}$ Even though the presence of social inequalities in cigarette smoking has been fully recognized in the international literature, ${ }^{5}$ to date, little research has examined the 
association between socioeconomic position (SEP) and tobacco use in Arab populations. Further, studies have not addressed the social context of cigarette smoking among women in countries with relatively high female prevalence, such as Jordan and Lebanon.

Evidence on the social determinants of tobacco use in low and middle-income countries shows that different social patterns emerge depending on the type of tobacco (smokeless, bidi, or cigarettes) and the SEP measure under investigation. ${ }^{6}$ In China and India, which have two of the highest rates of tobacco use worldwide, high education groups are less likely to smoke and more likely to quit than those with low education. ${ }^{6-8}$ In contrast to education, income exhibits a positive relationship with cigarette smoking among rural Chinese men. ${ }^{8}$ Moreover, the social patterning of tobacco use may be different for women than men. In Colombia for example, smoking in men shows inverse education and wealth gradient; cigarette smoking in women, however, exhibits a bell-shaped association with wealth and no association with education. ${ }^{9}$

Evidence suggests that social inequalities in tobacco use in low and middle-income countries begin to take shape as smoking rates decline and with the implementation of tobacco control policies. For example, in Madagascar, a country which only recently began to implement tobacco control policies, evidence shows no association between cigarette smoking and SEP among men. ${ }^{10}$ On the other hand, the declining cigarette smoking prevalence in Colombia has been primarily due to decreasing smoking among men in higher education and higher wealth groups. ${ }^{9}$

In this study, we explored the socioeconomic patterning of cigarette and WTS in women of reproductive age in Jordan. The prevalence of cigarette smoking in Jordan is $43.4 \%$ among men (the highest male prevalence in the Arab region) and $8.5 \%$ among women. ${ }^{11}$ Whereas the $8.5 \%$ prevalence among women is low in comparison to Europe and the United States, Jordanian women exhibit the second highest smoking rate in the Arab region after Lebanon. The prevalence of WTS in the general population in Jordan is uncertain, although two recent studies among university students have reported a very high overall rate of $42.7 \%$, with $64.4 \%$ of male students smoking waterpipe at least monthly. ${ }^{12,13}$

To our knowledge, socioeconomic inequalities in tobacco use in Jordan have not been examined based on representative data. Whether the social patterning of smoking in this upper middleincome country (http://data.worldbank.org/country/jordan) follows the established epidemic model, whereby tobacco use becomes increasingly concentrated in lower socioeconomic groups, has not yet been tested. We utilized four waves of the population-based Demographic and Health Surveys (DHS), which collect data primarily on women and children in developing countries, to examine whether tobacco use among Jordanian women is associated with social disadvantage, as in the case of high-income developed countries, or social advantage. Our study focused on two measures of SEP, education and household wealth, and two outcomes, cigarette smoking and WTS.

\section{Methods}

\section{Sample and Data}

This study is based on secondary analysis of four waves of the Jordan DHS gathered in $2002(N=5851), 2007(N=10654), 2009$ $(N=9879)$, and $2012(N=11$ 113). The DHS is an international program funded by the US Agency for International Development and collects nationally representative data on population, health, and nutrition in developing countries. Generally, DHS surveys include three validated questionnaires: a household questionnaire, a women's questionnaire, and a men's questionnaire. In Jordan, only the household and the women's questionnaires were used. As no data were collected on the health and nutrition of Jordanian men, our study is limited to women only. Response rates for the women's questionnaire for the four waves are: $97.6 \%$ in $2002 ; 97.9 \%$ in 2007 ; $97.2 \%$ in 2009 ; and $97.3 \%$ in 2012 .

All four waves of the Jordan DHS employed a stratified, twostage, geographically clustered sample design whereby each sampling unit (the household) had a defined probability of being selected. ${ }^{14}$ In the present study, two questionnaires were used, the household questionnaire and the women's questionnaire. The former collected basic demographic data on all members in the household as well as socioeconomic characteristics. Because questions in the DHS women's questionnaire focus on maternal and child health, only ever married women of reproductive age (15-49 years old) are included; unmarried women and those older than 49 are not. The Arabic questionnaire was pretested prior to fieldwork to ensure clarity and interviews were conducted by trained female field workers.

\section{Measures}

Our two main outcome measures, current cigarette and WTS, were ascertained by the two questions "Do you currently smoke cigarettes?" (yes or no) and "Do you currently smoke narghile?" (yes or no), respectively. "Narghile" is the local term given to the waterpipe. The two main independent variables examined were education and household wealth. Education level was coded into four categories: less than primary, completed primary, completed secondary, and higher than secondary. We used a measure on household wealth that was already computed and coded in each wave of the DHS data in five categories-poorest, poor, middle-income, rich, and richest. The wealth index is generated through running principal components analysis on a list of questions on household assets. For detailed information on principal components analysis in DHS and how the household wealth measure was created, see: http://dhsprogram.com/topics/wealth-index/. Other covariates included in the analysis are age in three categories (20-29, 30-39, or 40-49 years old), area of residence (rural or urban), and marital status (married or widowed/divorced/not living together). There were almost no missing data in outcome or independent variables in all survey waves (one observation had no smoking status recorded in 2009 and was excluded from the analysis). Given the focus of the study is on tobacco use (which is socially undesirable for adolescent girls in the context of Jordan) and in order to maintain equally sized age categories, we removed observations that were aged less than 20 years old. The number of observations removed prior to analysis was small: $2.6 \%$ in $2002,2.0 \%$ in $2007,2.3 \%$ in 2009 , and $2.1 \%$ in 2012. The final sample sizes were 5851 in 2002; 10654 in 2007; 9878 in 2009; and 11113 in 2012.

\section{Statistical Analysis}

We first estimated the prevalence of cigarette and WTS across all independent variables. Because our two outcome variables are binary, we used logistic regression in multivariable analyses. We specified a set of logistic regression models to assess the association between the two SEP measures (education and household wealth) and cigarette and WTS, adjusting for age, residence, and marital status. For this we pooled data from all four waves and reported adjusted odds ratios (AORs) and $95 \%$ confidence intervals (CIs). 
To test the interaction between time and SEP measures, we ran both time-unadjusted and time-adjusted logistic models for each outcome measure. We tested for multicollinearity between independent variables controlled for in our analysis; variance inflation factors between variables were all less than five, indicating that the assumption of reasonable independence was met. Sampling weights were used to account for the complex, multistage design of the DHS. We performed the statistical analyses using Stata 12 (StataCorp).

\section{Results}

\section{Sociodemographic Characteristics}

Table 1 shows the sociodemographic characteristics of Jordanian women in the four waves of DHS data. The average age of women was 33.7 (SD 7.6) in 2002, 34.3 (SD 7.7) in 2007, 34.2 (SD 7.8) in 2009, and 34.8 (SD 7.8) in 2012. The DHS samples included a majority urban population $(79.8 \%$ in $2002,85.0 \%$ in $2007,83.9 \%$ in 2009 , and $83.2 \%$ in 2012 ) and primarily married women; only around $5 \%$ of the sample in each year constituted women who are widowed, divorced, or separated. The sample distribution by education shows that, in each wave, at least $57 \%$ of Jordanian women had a secondary education and at least a quarter had more than secondary education; only a small proportion of women $(7.0 \%$ or lower in any given year) had less than a primary education.

\section{Cigarette and Waterpipe Tobacco Smoking Prevalence: Bivariate Results}

Table 2 shows the prevalence of cigarette and WTS among women overall and by sociodemographic characteristics. The overall prevalence of cigarette smoking among women was $10.0 \%$ in 2002 ,
$10.8 \%$ in $2007,8.9 \%$ in 2009 , and $10.9 \%$ in 2012 ; with the exception of a slight dip in 2009, cigarette smoking did not change much between 2002 and 2012. On the other hand, the prevalence of WTS increased across the data waves but remained lower than that of cigarette smoking in the first three: it was $4.1 \%$ in $2002,5.4 \%$ in 2007 , and $5.5 \%$ in 2009. In 2012, WTS was almost as high as cigarette smoking $(10.2 \%$ vs. $10.9 \%)$.

The table shows important differences in cigarette smoking prevalence by sociodemographic characteristics. Cigarette smoking increased in a stepwise manner with age in all four waves of data; it was also significantly higher among urban compared with rural residents, and among widowed, divorced, and separated women compared with married women. The prevalence of cigarette smoking was particularly high among widowed, divorced, and separated women in 2009 and 2012 (20.3\% and $27.3 \%$, respectively). WTS prevalence did not vary with age in 2002, 2007, and 2009; in 2012, it was significantly higher in the 20-29 year age group. Like cigarette smoking, WTS was also significantly higher among urban than rural residents in all waves of data. On the other hand, WTS did not vary with marital status except in 2012 where it was higher among widowed, divorced, and separated women.

Cigarette smoking displayed an inverse association with education (though not statistically significant in 2007) and a positive association with household wealth (statistically significant in all four waves). As education increased, there was a gradual decrease in cigarette smoking; prevalence decreased from $17.0 \%$ for less than primary to $9.1 \%$ for more than secondary in 2002 ; from $15.9 \%$ to $10.7 \%$ in 2007 ; and from $8.9 \%$ to $6.8 \%$ in 2009 . The change in prevalence was appreciable and highly significant in 2012, decreasing from $17.2 \%$ among women with less than primary education

Table 1. Sociodemographic Characteristics of Participants in the Jordan Demographic and Health Surveys (DHS) Samples, 2002, 2007, 2009, and 2012

\begin{tabular}{|c|c|c|c|c|}
\hline & 2002 & 2007 & 2009 & 2012 \\
\hline & $N=5851$ & $N=10654$ & $N=9879$ & $N=11113$ \\
\hline & $N(\%)$ & $N(\%)$ & $N(\%)$ & $N(\%)$ \\
\hline \multicolumn{5}{|l|}{ Age } \\
\hline $20-29$ & $1948(32.6)$ & $3286(30.6)$ & $3114(30.5)$ & $3300(29.0)$ \\
\hline $30-39$ & $2432(41.5)$ & $4314(40.1)$ & $3943(38.8)$ & $4333(38.2)$ \\
\hline $40-49$ & $1471(26.0)$ & $3054(29.4)$ & $2822(30.7)$ & $3480(32.7)$ \\
\hline \multicolumn{5}{|l|}{ Residence } \\
\hline Rural & $1775(20.2)$ & $3305(15.0)$ & $3125(16.1)$ & $3267(16.8)$ \\
\hline Urban & $4076(79.8)$ & $7349(85.0)$ & $6754(83.9)$ & $7846(83.2)$ \\
\hline \multicolumn{5}{|l|}{ Marital status } \\
\hline Married & $5575(94.9)$ & $10142(95.1)$ & $9416(95.4)$ & $10521(95.2)$ \\
\hline Widowed, divorced, separated & $276(5.1)$ & $512(4.9)$ & $463(4.6)$ & $592(4.9)$ \\
\hline \multicolumn{5}{|l|}{ Education } \\
\hline$<$ Primary & $521(6.2)$ & $741(3.9)$ & $522(2.8)$ & $407(2.4)$ \\
\hline Primary & $765(11.5)$ & $1011(7.5)$ & $897(7.1)$ & $962(7.6)$ \\
\hline Secondary & $3189(57.2)$ & $5934(58.8)$ & $5362(57.5)$ & $6197(58.6)$ \\
\hline$>$ Secondary & $1376(25.2)$ & $2968(29.8)$ & $3098(32.5)$ & $3547(31.4)$ \\
\hline \multicolumn{5}{|l|}{ Household wealth } \\
\hline Poorest & $1482(19.8)$ & $2968(20.1)$ & 2956 (19.2) & $2620(18.7)$ \\
\hline Poor & $1442(22.8)$ & $2646(21.0)$ & $2419(20.9)$ & $2824(20.5)$ \\
\hline Middle & $1176(20.6)$ & $2226(20.3)$ & $1998(20.7)$ & $2547(21.6)$ \\
\hline Rich & $1008(19.2)$ & $1704(19.7)$ & $1582(20.8)$ & $2020(20.6)$ \\
\hline Richest & $743(17.6)$ & $1110(18.9)$ & $924(18.4)$ & $1102(18.6)$ \\
\hline
\end{tabular}


Table 2. Prevalence of Cigarette and WTS by Sociodemographic Characteristics Across the Four Waves of Demographic and Health Surveys (DHS) Data

\begin{tabular}{|c|c|c|c|c|c|c|c|c|}
\hline & \multicolumn{2}{|c|}{2002} & \multicolumn{2}{|c|}{2007} & \multicolumn{2}{|c|}{2009} & \multicolumn{2}{|c|}{2012} \\
\hline & Cigarettes & WTS & Cigarettes & WTS & Cigarettes & WTS & Cigarettes & WTS \\
\hline & $N(\%)$ & $N(\%)$ & $N(\%)$ & $N(\%)$ & $N(\%)$ & $N(\%)$ & $N(\%)$ & $N(\%)$ \\
\hline Total sample & $547(10.0)$ & 175 (4.1) & $864(10.8)$ & $325(5.4)$ & $682(8.9)$ & $311(5.5)$ & $969(10.9)$ & $784(10.2)$ \\
\hline Age & * & & $* * *$ & & $* * *$ & & $* * *$ & $* *$ \\
\hline 20-29 & $139(8.0)$ & $66(4.9)$ & $149(6.9)$ & $98(4.6)$ & $128(5.4)$ & $119(6.5)$ & $212(8.0)$ & $290(12.7)$ \\
\hline $30-39$ & $238(10.7)$ & $81(4.2)$ & $358(11.0)$ & $136(5.9)$ & $233(8.1)$ & $106(5.0)$ & $340(9.4)$ & $284(9.1)$ \\
\hline $40-49$ & $170(11.4)$ & $28(2.9)$ & $357(14.6)$ & $91(5.6)$ & $321(13.3)$ & $86(5.0)$ & $417(15.1)$ & $210(9.2)$ \\
\hline Residence & * & $* * *$ & $* * *$ & $* * *$ & $* * *$ & $* * *$ & $* * *$ & $* * *$ \\
\hline Rural & $147(7.8)$ & $24(1.6)$ & $222(6.5)$ & 48 (1.7) & $161(5.4)$ & $33(1.1)$ & $181(6.4)$ & $128(4.5)$ \\
\hline Urban & $400(10.6)$ & $151(4.7)$ & $642(11.6)$ & $277(6.1)$ & $521(9.6)$ & $278(6.3)$ & $788(11.8)$ & $656(11.3)$ \\
\hline Marital status & $* * *$ & & $* * *$ & & $* * *$ & & $* * *$ & $*$ \\
\hline Married & $495(9.5)$ & $164(3.9)$ & $770(10.4)$ & $308(5.5)$ & $610(8.4)$ & $293(5.4)$ & $861(10.0)$ & $730(9.9)$ \\
\hline Widowed, divorced, separated & $52(19.0)$ & $11(6.6)$ & $94(18.4)$ & 17 (4.6) & $72(20.3)$ & $18(7.4)$ & $108(27.3)$ & $54(15.4)$ \\
\hline Education & $*$ & $*$ & & $*$ & $*$ & $*$ & $* * *$ & $*$ \\
\hline$<$ Primary & $94(17.0)$ & $7(2.1)$ & $117(15.9)$ & $5(0.9)$ & $64(8.9)$ & $1(0.2)$ & $52(17.2)$ & $6(2.6)$ \\
\hline Primary & $73(9.0)$ & $10(1.3)$ & $114(13.5)$ & $19(3.0)$ & $81(9.4)$ & $19(3.0)$ & $133(16.1)$ & $48(6.6)$ \\
\hline Secondary & $282(9.8)$ & $113(4.5)$ & $431(10.2)$ & $193(5.6)$ & $394(10.0)$ & $188(6.2)$ & $592(11.8)$ & $467(11.4)$ \\
\hline$>$ Secondary & $97(9.1)$ & $45(4.8)$ & $202(10.7)$ & $108(6.2)$ & $143(6.8)$ & $103(5.2)$ & $188(7.4)$ & $263(9.4)$ \\
\hline Household wealth & $* * *$ & $* * *$ & $* * *$ & $* * *$ & $* * *$ & $* * *$ & $* *$ & $* * *$ \\
\hline Poorest & $151(9.3)$ & $28(2.7)$ & $214(8.6)$ & $43(2.9)$ & $169(6.3)$ & $34(2.0)$ & $244(10.9)$ & $99(5.6)$ \\
\hline Poor & $106(7.5)$ & $22(1.7)$ & $164(7.6)$ & $54(2.7)$ & $137(6.2)$ & $46(2.7)$ & $216(10.9)$ & $129(6.9)$ \\
\hline Middle & $85(7.6)$ & $34(3.6)$ & $178(10.0)$ & $55(3.4)$ & $135(7.8)$ & $68(4.8)$ & $199(8.9)$ & $187(9.4)$ \\
\hline Rich & $108(12.1)$ & $39(4.6)$ & $147(10.8)$ & $78(6.8)$ & $123(10.7)$ & $73(6.0)$ & $161(8.8)$ & $193(11.2)$ \\
\hline Richest & $97(14.6)$ & $52(8.8)$ & $161(17.6)$ & $95(11.9)$ & $118(13.8)$ & $90(12.4)$ & $149(15.5)$ & $176(18.3)$ \\
\hline
\end{tabular}

$* P<.05 ; * P<.01 ; * * P<.001$ chi-squared for differences in proportion by groups.

to $7.4 \%$ among women with more than secondary education. Conversely, cigarette smoking significantly increased with increasing household wealth: from $9.3 \%$ among the poorest to $14.6 \%$ among the richest in 2002 ; from $8.6 \%$ to $17.6 \%$ in 2007 ; from $6.3 \%$ to $13.8 \%$ in 2009 ; and from $10.9 \%$ to $15.5 \%$ in 2012 .

WTS displayed a positive association with both education and household wealth. Prevalence increased from $2.1 \%$ for less than primary to $4.8 \%$ for more than secondary in 2002 ; from $0.9 \%$ to $6.2 \%$ in 2007 ; from $0.2 \%$ to $5.2 \%$ in 2009 ; and from $2.6 \%$ to $9.4 \%$ in 2012. Similarly, the prevalence of WTS increased from $2.7 \%$ among the poorest to $8.8 \%$ among the richest in 2002 ; from $2.9 \%$ to $11.9 \%$ in 2007 ; from $2.0 \%$ to $12.4 \%$ in 2009 ; and from $5.6 \%$ to $18.3 \%$ in 2012 .

\section{Multivariable Results}

Table 3 presents the results of pooled logistic regression models specified to predict the odds of tobacco smoking by education and household wealth, adjusting for age, urban versus rural residence, and marital status. The time-unadjusted (1) and time-adjusted (2) models show near-identical odds ratios. Logistic regression models for individual years can be found in Supplementary Tables 1 and 2 .

In the time-adjusted Model 2, increasing age significantly predicted higher odds of cigarette smoking. As expected, urban residence and being widowed, divorced, or separated significantly predicted higher odds of cigarette smoking compared to rural residence and being married, respectively.

Increasing education significantly predicted lower odds of cigarette smoking. Compared to women in the lowest education category (less than primary), the odds of cigarette smoking were lower among women with a primary education $(A O R=0.74 ; 95 \% \mathrm{CI}=0.55 \%$ to $1.00 \%)$, secondary education $(A O R=0.62 ; 95 \% \mathrm{CI}=0.48 \%$ to $0.81 \%)$ and more than secondary education $(A O R=0.41 ; 95 \%$ $\mathrm{CI}=0.31 \%$ to $0.55 \%)$. Conversely, household wealth displayed a positive association with cigarette smoking; the odds were significantly higher among the rich $(A O R=1.30 ; 95 \% \mathrm{CI}=1.06 \%$ to $1.58 \%)$ and richest $(A O R=2.09 ; 95 \% \mathrm{CI}=1.70 \%$ to $2.56 \%)$ compared with the poorest group. Time did not have an effect on cigarette smoking; the odds of smoking cigarettes did not significantly change between 2002 and 2012.

Table 3 also presents the results of time-unadjusted (1) and timeadjusted (2) logistic regression models specified to predict the odds of WTS. Increasing age predicted a lower likelihood of WTS. The odds of WTS were significantly higher among urban compared with rural residents, and higher among widowed, divorced, or separated women compared with married women.

In contrast to cigarettes, increasing education predicted higher odds of WTS. However, the odds ratios were weak and only significant for those with secondary education, compared with those with less than primary education $(A O R=2.54,95 \% \mathrm{CI}=1.23 \%$ to $5.25 \%$ ). Household wealth displayed a strong positive association with WTS; the odds were significantly higher among the middle $(A O R=1.59,95 \% \mathrm{CI}=1.23 \%$ to $2.06 \%)$, rich $(A O R=2.23,95 \%$ $\mathrm{CI}=1.68 \%$ to $2.97 \%)$ and richest $(A O R=4.51,95 \% \mathrm{CI}=3.37 \%$ to $6.03 \%$ ) groups compared with the poorest. Finally, unlike in the case of cigarette smoking, time exhibited a significant effect on WTS. The odds of smoking waterpipe increased between 2002 and 2012. In particular, the odds of WTS were almost three times higher in 2012 compared with $2002(A O R=2.66,95 \% \mathrm{CI}=2.08 \%$ to $3.39 \%)$. 
Table 3.Time-Unadjusted (Model 1) andTime-Adjusted (Model 2) Predictors of the Tobacco Use Among Women in Jordan

\begin{tabular}{|c|c|c|c|c|c|c|c|c|}
\hline & \multicolumn{4}{|c|}{ Cigarettes } & \multicolumn{4}{|c|}{ Waterpipe } \\
\hline & \multicolumn{2}{|c|}{ Model 1} & \multicolumn{2}{|c|}{ Model 2} & \multicolumn{2}{|c|}{ Model 1} & \multicolumn{2}{|c|}{ Model 2} \\
\hline & $A O R$ & $95 \% \mathrm{CI}$ & $A O R$ & $95 \% \mathrm{CI}$ & $A O R$ & $95 \% \mathrm{CI}$ & $A O R$ & $95 \% \mathrm{CI}$ \\
\hline \multicolumn{9}{|l|}{ Age } \\
\hline $20-29$ & 1.00 & Ref. & 1.00 & Ref. & 1.00 & Ref. & 1.00 & Ref. \\
\hline $30-39$ & 1.36 & $1.18,1.58 * *$ & 1.36 & $1.17,1.58 * * *$ & 0.77 & $0.64,0.92 * *$ & 0.76 & $0.63,0.91 *$ \\
\hline $40-49$ & 1.73 & $1.49,2.02 * * *$ & 1.73 & $1.48,2.02 * * *$ & 0.65 & $0.53,0.80 * * *$ & 0.62 & $0.51,0.77 * * *$ \\
\hline \multicolumn{9}{|l|}{ Residence } \\
\hline Rural & 1.00 & Ref. & 1.00 & Ref. & 1.00 & Ref. & 1.00 & Ref. \\
\hline Urban & 1.64 & $1.41,1.90 * * *$ & 1.63 & $1.41,1.89 * * *$ & 2.31 & $1.89,2.82 * * *$ & 2.33 & $1.92,2.83 * * *$ \\
\hline \multicolumn{9}{|l|}{ Marital status } \\
\hline Married & 1.00 & Ref. & 1.00 & Ref. & 1.00 & Ref. & 1.00 & Ref. \\
\hline Widowed, divorced, separated & 2.25 & $1.80,2.82 * * *$ & 2.26 & $1.81,2.82 * * *$ & 1.59 & $1.16,2.17 * *$ & 1.66 & $1.20,2.23 * *$ \\
\hline \multicolumn{9}{|l|}{ Education } \\
\hline$<$ Primary & 1.00 & Ref. & 1.00 & Ref. & 1.00 & Ref. & 1.00 & Ref. \\
\hline Primary & 0.74 & $0.55,1.00 *$ & 0.74 & $0.55,1.00 *$ & 1.85 & $0.91,3.78$ & 1.73 & $0.84,3.58$ \\
\hline Secondary & 0.63 & $0.48,0.81 * * *$ & 0.62 & $0.48,0.81 * * *$ & 2.85 & $1.40,5.78^{*}$ & 2.54 & $1.23,5.25^{*}$ \\
\hline$>$ Secondary & 0.41 & $0.31,0.55^{* * *}$ & 0.41 & $0.31,0.55^{* * *}$ & 1.92 & $0.94,3.94$ & 1.68 & $0.80,3.50$ \\
\hline \multicolumn{9}{|l|}{ Household wealth } \\
\hline Poorest & 1.00 & Ref. & 1.00 & Ref. & 1.00 & Ref. & 1.00 & Ref. \\
\hline Poor & 0.98 & $0.83,1.16$ & 0.98 & $0.83,1.16$ & 1.02 & $0.75,1.39$ & 1.05 & $0.77,1.42$ \\
\hline Middle & 1.07 & $0.89,1.29$ & 1.08 & $0.90,1.29$ & 1.57 & $1.22,2.04 * * *$ & 1.59 & $1.23,2.06 * * *$ \\
\hline Rich & 1.29 & $1.06,1.57^{*}$ & 1.30 & $1.06,1.58^{*}$ & 2.19 & $1.66,2.89 * * *$ & 2.23 & $1.68,2.97 * * *$ \\
\hline Richest & 2.08 & $1.69,2.55^{* * *}$ & 2.09 & $1.70,2.56^{* * *}$ & 4.33 & $3.27,5.75 * *$ & 4.51 & $3.37,6.03 * * *$ \\
\hline \multicolumn{9}{|l|}{ Time (year) } \\
\hline 2002 & - & - & 1.00 & Ref. & - & - & 1.00 & Ref. \\
\hline 2007 & - & - & 1.09 & $0.91,1.30$ & - & - & 1.29 & $0.99,1.68$ \\
\hline 2009 & - & - & 0.89 & $0.75,1.07$ & - & - & 1.31 & $1.01,1.70 *$ \\
\hline 2012 & - & - & 1.11 & $0.92,1.35$ & - & - & 2.66 & $2.08,3.39 * * *$ \\
\hline
\end{tabular}

$A O R=$ adjusted odds ratio; $\mathrm{CI}=$ confidence interval.

*P<.05;* $* P<.01 ; * * P<.001$.

\section{Discussion}

This study is the first to explore the social patterning of cigarette and WTS among Jordanian women using two SEP measures, education and household wealth. Our results show that, with the exception of a slight drop in 2009, the prevalence of cigarette smoking hovered around $10 \%$ between 2002 and 2012, a rate that is slightly higher than the $8.5 \%$ reported by $\mathrm{Ng}$ and colleagues. ${ }^{11}$ The higher prevalence of cigarette smoking among older women could mean that younger cohorts are initiating the habit less, and that cigarette smoking prevalence may decrease over time. This is cause for optimism. On the other hand, the age pattern could indicate that women in Jordan initiate smoking in their thirties and forties because of social restrictions placed on younger women; the almost constant overall prevalence of cigarette smoking between 2002 and 2012 lends support to this potential explanation (see results in Supplementary Tables 1 and 2). These two interpretations remain speculative as the DHS does not include data on age of smoking initiation.

Though cigarette smoking prevalence among Jordanian women has not increased between 2002 and 2012, WTS prevalence has increased, particularly between 2009 and 2012. In contrast to cigarettes, younger women smoke waterpipe more than older women. This pattern corroborates results revealed in other studies among Jordanian university students, which show that WTS is almost equally high among females as males, ${ }^{12,13}$ as well as those from studies on youth WTS in Western countries. ${ }^{15-17}$ The rapid surge in WTS particularly among young people worldwide is alarming in light of evidence highlighting its negative health outcomes. ${ }^{18}$

Our findings show that cigarette and WTS among women in Jordan exhibit a complex social patterning by education and household wealth. Education clearly protects against cigarette smoking but does not exert the same protective effect on WTS. Increasing household wealth, on the other hand, exerts a negative effect on both forms of tobacco use, with wealth showing a particularly deleterious effect on WTS. This social patterning is at odds with the established smoking epidemic model in developed countries that has shown a concentration of tobacco-use among low SEP groups. ${ }^{19}$ It is important to keep in mind that the DHS does not include data on men and our findings reveal the social patterning of tobacco-use among women only. As evidence from European studies has shown that the socioeconomic crossover in cigarette smoking took place among men first, the social patterning of tobacco-use among Jordanian men may already show an inverse social gradient. This question deserves further empirical examination using other data sets.

That the effect of wealth on cigarette and WTS diverges from that of education in Jordan highlights that each measure captures a different underlying concept of SES. Though evidence on the differential impact of education and wealth on chronic disease risk factors has received scholarly attention in high-income countries, ${ }^{20}$ we were able to identify only one recent study that addressed this question in the Arab region. In examining the social patterning of obesity in Egypt, Aitsi-Selmi and colleagues ${ }^{21}$ revealed that, whereas education 
exerts a protective effect, higher wealth is a risk factor for obesity particularly among women with low education. The authors conjectured that being wealthy in a low-income country may promote poor dietary habits such as eating fast food; however, higher education may protect against this risk by positively informing dietary choices. Similarly, in Jordan, while women in higher wealth groups may associate cigarette smoking with modernity or female autonomy, ${ }^{22}$ higher education may inform healthier decisions with respect to smoking.

The positive association between wealth and tobacco use is a pattern generally observed for developing countries, and is more pronounced in the lowest income countries compared with uppermiddle-income countries. ${ }^{23}$ It is paradoxical that in Jordan, an upper middle-income country that has had a long history of implementing tobacco control measures, ${ }^{24}$ tobacco use displays a social patterning characteristic of low-income countries when wealth is the SES measure used. In addition to SES, cultural factors are critical to understanding the drivers of cigarette and WTS among wealthier Jordanian women. Our findings reinforce the notion that cigarette smoking among Arab women is perceived to project wealth, independence, and a "modern" cultural orientation. The interaction between culture and SES is more complex in the case of WTS as women usually consume WTS in trendy cafés that serve as social outlets for primarily young people of middle- to high-income classes. A study in Lebanon reported that young women generally perceive WTS as a "fashionable" activity. ${ }^{25}$ This cultural perception exists in Jordan as well but is also variegated by social class. Ironically, the pattern in WTS in Jordan reflects the fact that advantaged women exhibit more control over their behavior in public, including that of WTS.

Existing tobacco legislation should be examined to understand why cigarette smoking among Jordanian women has shown no sign of abatement during the past decade and, particularly, why WTS is on the rise. Currently, women in the wealthiest households use tobacco at higher rates and it may seem tempting to target this group in particular or to respond with traditional awareness-raising interventions. The country's policy makers, however, can learn from the experiences of other high and middle-income countries that have implemented awareness-raising tobacco control programs. Evidence has shown that these types of control efforts can in fact contribute to a gradual concentration of the behavior in the most disadvantaged groups in society. ${ }^{26}$ As the two main goals of public health are: (1) to reduce poor health outcomes and (2) to diminish social inequalities in these health outcomes, equity-centered policies and approaches are needed. Systematic reviews have shown that, in contrast to individually-based awareness-raising interventions, increasing the price of tobacco products is effective in reducing both the prevalence of and social inequalities in tobacco use. ${ }^{27}$ In the case of Jordan, monitoring cigarette and WTS rates, in addition to monitoring inequalities in these two behavioral outcomes by education and wealth, are important first steps on the road to implementing informed policies.

One of the strengths of our study is that it is based on an analysis of four waves of nationally-representative data. Nonetheless, the study has some limitations. First and foremost, the DHS does not include data on men and our findings apply to Jordanian women only. Furthermore, our study focused on "conventional" cigarette and WTS only as questions on the use of other tobacco products and electronic cigarettes were not asked in any of the four waves of DHS. In contrast to European research that has increasingly paid attention to electronic cigarettes, ${ }^{28}$ very little evidence on this form of smoking is available in Arab countries. It appears that the electronic cigarettes are rarely used in the region, perhaps due to weak indoor smoking legislation and the increasing trend of WTS in indoor and outdoor cafes. Another limitation is that our outcome measures are self-reported and unverified, which may under-report prevalence, particularly given the social unacceptability of cigarette use among younger women. A final limitation is that DHS surveys lack important data on patterns of tobacco use, such as initiation age and volume of use. In conclusion, our study revealed that educational attainment is protective against cigarette smoking but not WTS. On the other hand, both cigarette and WTS in Jordan are more prevalent among the wealthy, and that increasing wealth exerts a deleterious effect on WTS in particular. Equity-centered tobacco control efforts in Jordan should focus on lowering cigarette and WTS prevalence while, at the same time, preempting the rise in social inequalities in tobacco use.

\section{Supplementary Material}

Supplementary Tables 1 and 2 can be found online at http://www. ntr.oxfordjournals.org

\section{Funding}

None declared.

\section{Declaration of Interests}

None declared.

\section{Acknowledgments}

MJ was supported by a Daniel Turnberg UK/Middle East Travel Fellowship. SA is a member of the RESCAP-Med network and this study is part of her research on the social determinants of NCDs and NCD risk factors. AD's contribution to this study came as part of his graduate student assistantship paid by the Faculty of Health Sciences at the American University of Beirut.

\section{References}

1. Rahim HFA, Sibai A, Khader Y, et al. Non-communicable diseases in the Arab world. Lancet. 2014;383(9914):356-367. doi:10.1016/ S0140-6736(13)62383-1.

2. Mokdad AH, Jaber S, Aziz MIA, et al. The state of health in the Arab world, 1990-2010: an analysis of the burden of diseases, injuries, and risk factors. Lancet. 2014;383(9914):309-320. doi:10.1016/S0140-6736(13)62189-3.

3. Akl EA, Gunukula SK, Aleem S, et al. The prevalence of waterpipe tobacco smoking among the general and specific populations: a systematic review. BMC Public Health. 2011;11. doi:10.1186/1471-2458-11-244.

4. Maziak W. The global epidemic of waterpipe smoking. Addict Behav. 2011;36(1-2):1-5. doi:10.1016/j.addbeh.2010.08.030.

5. Poland B, Frohlich K, Haines RJ, Mykhalovskiy E, Rock M, Sparks R. The social context of smoking: the next frontier in tobacco control? Tob Control. 2006;15(1):59-63. doi:10.1136/tc.2004.009886.

6. Sorensen G, Gupta PC, Pednekar MS. Social disparities in tobacco use in Mumbai, India: the roles of occupation, education, and gender. Am J Public Health. 2005;95(6):1003-1008. doi:10.2105/AJPH.2004.045039.

7. Corsi DJ, Subramanian S, Lear SA, et al. Tobacco use, smoking quit rates, and socioeconomic patterning among men and women: a cross-sectional survey in rural Andhra Pradesh, India. Eur J Prev Cardiol. 2013;0(00):111. doi:10.1177/2047487313491356.

8. Yang T, Li F, Yang X, et al. Smoking patterns and sociodemographic factors associated with tobacco use among Chinese rural male 
residents: a descriptive analysis. BMC Public Health. 2008;8(1):248. doi:10.1186/1471-2458-8-248.

9. Macías F, Malmusi D, Borrell C. Different patterns by age-group and gender of socioeconomic inequalities in smoking in Colombia. Nicotine Tob Res. 2013;15(10):1745-1755. doi:10.1093/ntr/ntt055.

10. Blecher E, Liber AC, Chaussard M, Fedewa S. Market structures, socioeconomics, and tobacco usage patterns in Madagascar. Nicotine Tob Res. 2014;16(suppl 1):S56-S64. doi:10.1093/ntr/ntt020.

11. Ng M, Freeman MK, Fleming TD, et al. Smoking prevalence and cigarette consumption in 187 countries, 1980-2012. JAMA. 2014;311(2):183-192. doi:10.1001/jama.2013.284692.

12. Azab M, Khabour F, Alkaraki K, Eissenberg T, Alzoubi H, Primack A. Water pipe tobacco smoking among university students in Jordan. Nicotine Tob Res. 2010;12(6):606-612. doi:10.1093/ntr/ntq055.

13. Dar-Odeh S, Bakri G, Al-Omiri K, et al. Narghile (water pipe) smoking among university students in Jordan: Prevalence, pattern and beliefs. Harm Reduct J. 2010;7:10. doi:10.1186/1477-7517-7-10.

14. DHS Methodology. The DHS Program: Demographic and Health Surveys [online]. 2014. http://dhsprogram.com/What-We-Do/Survey-Types/DHSMethodology.cfm. Accessed May 29, 2015.

15. Mzayek F, Khader Y, Eissenberg T, Ali RA, Ward KD, Maziak W. Patterns of water-pipe and cigarette smoking initiation in schoolchildren: Irbid longitudinal smoking study. Nicotine Tob Res. 2012;14(4):448-454. doi:10.1093/ntr/ntr234.

16. Smith JR, Edland SD, Novotny TE, et al. Increasing hookah use in California. Am J Public Health. 2011;101(10):1876-1879. doi:10.2105/ AJPH.2011.300196.

17. Warren C, Riley L, Asma S, et al. Tobacco use by youth: a sureillance report from the global youth tobacco survey. Bull World Health Organ. 2000;78(7):868-876.

18. Akl EA, Gaddam S, Gunukula SK, Honeine R, Jaoude PA, Irani J. The effects of waterpipe tobacco smoking on health outcomes: a systematic review. Int J Epidemiol. 2010;39(3):834-857. doi:10.1093/ije/dyq002.

19. Corsi DK, Boyle MH, Lear SA, Chow CK, Teo KK, Subramanian SV. Trends in smoking in Canada from 1950-2011: progression of the tobacco epidemic according to socioeconomic status and geography. Cancer Causes Control. 2014;25(1):45-57. doi:10.1007/s10552-013-0307-9.

20. Geyer S, Hemström Ö, Peter R, Vågerö D. Education, income, and occupational class cannot be used interchangeably in social epidemiology. Empirical evidence against a common practice. J Epidemiol Community Health. 2006;60(9):804-810. doi:10.1136/jech.2005.041319.

21. Aitsi-Selmi A, Chandola T, Friel S, Nouraei R, Shipley MJ, Marmot MG. Interaction between Education and Household Wealth on the Risk of Obesity in Women in Egypt. PLoS ONE. 2012;7(6):e39507. doi:10.1371/ journal.pone.0039507.

22. Afifi RA, Nakkash RT, Khawaja M. Social capital, women's autonomy and smoking among married women in low-income urban neighborhoods of Beirut, Lebanon. Womens Health Issues. 2010;20(2):156-167. doi:10.1016/j.whi.2009.12.005.

23. Pampel F, Denney J. Cross-national sources of health inequality: education and tobacco use in the World Health Survey. Demography. 2011;48(2):653-674. doi:10.1007/s13524-011-0027-2.

24. Belbeisi A, Al Nsour M, Batieha A, Brown D, Walke H. A surveillance summary of smoking and review of tobacco control in Jordan. Global Health. 2009;5(1):18. doi:10.1186/1744-8603-5-18.

25. Chaaya M, Jabbour S, El-Roueiheb Z, Chemaitelly H. Knowledge, attitudes, and practices of argileh (water pipe or hubble-bubble) and cigarette smoking among pregnant women in Lebanon. Addict Behav. 2004;29(9):1821-1831. doi:10.1016/j.addbeh.2004.04.008.

26. Schulze A, Mons U. The evolution of educational inequalities in smoking: a changing relationship and a cross-over effect among German birth cohorts of 1921-70. Addiction. 2006;101(7):1051-1056. doi:10.1111/j.1360-0443.2006.01458.x.

27. Thomas S, Fayter D, Misso K, et al. Population tobacco control interventions and their effects on social inequalities in smoking: systematic review. Tob Control. 2008;17(4):230-237. doi:10.1136/tc.2007.023911.

28. Vardavas CI, Filippidis FT, Agaku IT. Determinants and prevalence of e-cigaretee use throughout the European Union: a secondary analysis of 26566 youth and adults from 27 countries. Tob Control. 2014. [Epub ahead of print]. doi:10.1136/tobaccocontrol-2013-051394. 